Article

\title{
Comparing Endovascular Treatment Methods in Acute Ischemic Stroke Due to Tandem Occlusion Focusing on Clinical Aspects
}

\author{
Peter Janos Kalmar ${ }^{1}$, Gabor Tarkanyi ${ }^{1}$, Csaba Balazs Nagy ${ }^{2}$, Peter Csecsei ${ }^{2}$, Gabor Lenzser ${ }^{2}$, Edit Bosnyak ${ }^{1}$, \\ Zsofia Nozomi Karadi ${ }^{1}$, Adam Annus ${ }^{3}{ }^{-}$, Istvan Szegedi ${ }^{4}{ }^{\circ}$, Andras Buki ${ }^{2}$ and Laszlo Szapary ${ }^{1, *}$ \\ 1 Department of Neurology, Medical School, University of Pécs, 7623 Pécs, Hungary; \\ kalmar.peterj@gmail.com (P.J.K.); tarkanyigabor@indamail.hu (G.T.); bosnyak.edit@pte.hu (E.B.); \\ karadi.zsofia@pte.hu (Z.N.K.) \\ 2 Department of Neurosurgery, Medical School, University of Pécs, 7623 Pécs, Hungary; \\ nagy.csaba2@pte.hu (C.B.N.); csecseipeti@yahoo.com (P.C.); lenzser.gabor@pte.hu (G.L.); \\ buki.andras@pte.hu (A.B.) \\ 3 Department of Neurology, University of Szeged, 6725 Szeged, Hungary; annus.adam@med.u-szeged.hu \\ 4 Department of Neurology, University of Debrecen, 4032 Debrecen, Hungary; szegedi.istvan@med.unideb.hu \\ * Correspondence: szapary.laszlo@pte.hu or ptestroke@gmail.com
}

check for updates

Citation: Kalmar, P.J.; Tarkanyi, G.; Nagy, C.B.; Csecsei, P.; Lenzser, G.; Bosnyak, E.; Karadi, Z.N.; Annus, A.; Szegedi, I.; Buki, A.; et al. Comparing Endovascular Treatment Methods in Acute Ischemic Stroke Due to Tandem Occlusion Focusing on Clinical Aspects. Life 2021, 11, 458. https:// doi.org/10.3390/life11050458

Academic Editors: Gergely Fehér, Péter Klivényi, Joel Rodriguez-Saldana and Alexey V. Polonikov

Received: 23 April 2021

Accepted: 14 May 2021

Published: 20 May 2021

Publisher's Note: MDPI stays neutral with regard to jurisdictional claims in published maps and institutional affiliations.

Copyright: () 2021 by the authors. Licensee MDPI, Basel, Switzerland. This article is an open access article distributed under the terms and conditions of the Creative Commons Attribution (CC BY) license (https:// creativecommons.org/licenses/by/ $4.0 /)$.
Abstract: Introduction: Acute ischemic strokes (AIS) due to tandem occlusion (TO) of intracranial anterior large vessel and concomitant extracranial internal carotid artery (EICA) are represent in $15-20 \%$ of all ischemic strokes. The endovascular treatment (EVT) strategy for those patients is still unclear. Although the intracranial mechanical thrombectomy (MT) is considered as a standard treatment approach, the EICA lesion stent necessity remains a matter of debate. We sought to assess the efficacy and safety of EVT in tandem lesions, particularly the EICA stenting management. Methods: We retrospectively analyzed all patients with anterior circulation stroke associated with EICA lesion and receiving EVT in the three participated stroke centers between November 2017 and December 2020. Patients' data were collected from our prospective stroke registry (STAY ALIVE). Patients enrolled in our study were divided into two groups depending on whether acute carotid stenting (ACS) or balloon angioplasty only (BAO) technique was used. Our primary outcome was the 90-day functional outcome assessed by modified Rankin scale (mRS). Mortality at 90 days and symptomatic intracranial hemorrhage $(\mathrm{sICH})$ were considered as secondary outcomes. Results: A total of 101 patients (age: $67 \pm 10$ years, 38.6\% female) were enrolled in our study, including 29 (28.3\%) BAO cases, and 72 (71.3\%) patients treated with ACS. Patients in the BAO group were slightly older (70 \pm 9 years vs. $66 \pm 10$ years, $p=0.054$ ), and had higher prevalence of comorbidities such as hypertension $(100.0 \%$ vs. $59.4 \%, p<0.001)$. There was no significant difference in favorable outcomes $(51.7 \%$ vs. $54.4 \%, p=0.808)$ between the groups. However, we observed a trend towards higher rates of $\operatorname{sICH}(8.3 \%$ vs. $3.4 \%, p=0.382)$ and 90 -day mortality $(23.5 \%$ vs. $13.8 \%, p=0.278)$ with significantly higher frequency of distal embolization $(39.1 \%$ vs. $17.9 \%, p=0.043)$ in patients with ACS. In the overall population age $(p=0.013)$, atrial fibrillation (AF) $(p=0.008)$, National Institutes of Health Stroke Scale (NIHSS) baseline $(p=0.029)$, and successful recanalization $(p=0.023)$ were associated with favorable outcome. Conclusion: Endovascular approach of EICA in addition to MT was safe and effective in tandem occlusion of anterior circulation. Furthermore, our results suggest that balloon angioplasty technique without acute stenting shows a comparable favorable outcome rate to ACS with moderately less hemorrhagic events and mortality rates.

Keywords: stroke; tandem occlusion; endovascular treatment; thrombectomy; acute stenting

\section{Introduction}

Acute ischemic stroke (AIS) due to tandem occlusion (TO) is defined as high grade stenosis or occlusion of the cervical segment of the internal carotid artery (ICA) associated 
with concurrent ipsilateral intracranial large vessel occlusion (LVO) along the anterior cerebral circulation (primarily in the distal ICA or middle cerebral artery (MCA) segments) [1,2]. This type of AIS accounts for 15-20\% of all ischemic strokes [3]. Approximately $40-69 \%$ of these patients survive with severe neurological deficits or die without effective treatment [4].

Recent randomized-controlled trials (RCT) have shown the efficacy and safety of endovascular treatment (EVT) of LVO in the anterior circulation [5-7]. However, in these trials, patients with TO were usually excluded (SWIFT PRIME, EXTEND-IA) or poorly represented (18.3\% in REVASCAT, $17 \%$ in ESCAPE) due to the greater stroke severity and complex endovascular technique of TO [5,7-10]. Consequently, endovascular treatment (EVT) of patients with TO is mostly described in small and retrospective single-center studies, therefore, there is a lack of strong evidence for the optimal management of this subtype. Current guidelines recommend performing mechanical thrombectomy (MT) if it is reasonable and administering intravenous thrombolysis (IVT) in every eligible patient [11]. However, IVT has moderate recanalization success in tandem lesions (achieves recanalization in only 9-22\%), depending on the site of occlusion [12-14]. Furthermore, currently there is no consensus on the ideal technical interventional strategy. Multiple endovascular treatment strategies have been described: balloon angioplasty with or without emergent carotid artery stenting of the extracranial ICA (EICA) preceded or followed by MT [15]. However, the appropriate patient population for the different endovascular strategies are still unclear [16-19].

The aim of our study was to compare the efficacy and safety of acute carotid stenting (ACS) and balloon angioplasty only (BAO) techniques in patients with AIS due to atherothrombotic anterior tandem occlusion.

\section{Methods}

\subsection{Study Population}

This multicenter-study was based on three major stroke institutions' prospective clinical registry (STAY ALIVE Acute Stroke Registry). Research protocol was approved by the local ethics committee. For all patients enrolled in the study, written consent was given in accordance with Good Clinical Practice (GCP) guidelines.

All consecutive patients with acute stroke due to TO and have received EVT between November 2017 and December 2020 were screened and retrospectively analyzed. TO was defined as an occlusion or high-grade stenosis (NASCET (North American Symptomatic Carotid Endarterectomy Trial) $>70 \%$ ) of EICA with a concomitant ipsilateral intracranial LVO (terminal segment of ICA (tICA), MCA M1 or M2 branch) [20].

Patients meeting the following criteria were included: (1) age over 18 years; (2) acute stroke symptoms with baseline National Institutes of Health Stroke Scale (NIHSS) $>4$ or isolated aphasia or hemianopia was recognized; (3) symptom onset was no longer than $24 \mathrm{~h}$; (4) TO confirmed by either CT angiography, peri-interventional angiograms, or both; and (5) acute EVT with ACS or BAO of EICA and intracranial MT. Cases of primary ACS or BAO without intracranial MT or occlusion due to EICA dissection were excluded. Furthermore, datasets including inconsistent information were also excluded.

We collected the following data: demographic variables; vascular risk factors; medication therapy; stroke severity (National Institutes of Health Stroke Scale (NIHSS) score); baseline clinical and labor parameters; admission and control imaging data (Alberta Stroke Program Early CT Score (ASPECTS); multiphase CT-angiography (mCTA) collateral score; time metrics; interventional techniques features and complications.

\subsection{Diagnosis}

Patients either arrived primarily in the emergency department of the major neurovascular centers (primary transport) or within the hospitals of surrounding cities and were transferred to the major stroke centers (secondary transport). 
Baseline NIHSS was evaluated by a dedicated stroke neurologist on admission. Every patient underwent CT angiography under the center's protocol for AIS, to assess the intracranial LVO and EICA lesion, and to exclude intracranial hemorrhage. If TO was suspected from the initial CT image, it was confirmed with digital subtraction angiography (DSA).

\subsection{Thrombolysis}

IVT was administered $(0.9 \mathrm{mg} / \mathrm{kg})$ in every eligible patient within a maximum $4.5 \mathrm{~h}$ after stroke onset (clinical and laboratory inclusion and exclusion criteria for IVT were applied).

\subsection{Endovascular Technique}

EVT was performed under conscious sedation or general anesthesia. This decision was made by the neurointerventional specialist and the anesthesiologist on call. DSA was performed with transfemoral approach; if this was not feasible, we chose radial approach. Biplane angiography was used for the intervention. After the local anesthesia in the inguinal region, an 8F guiding or balloon-guiding catheter (Neuronmax, Penumbra, Alameda, CA, USA; Guider Softip, Boston Scientific, Marlborough, MA, USA; Flowgate 2, Stryker, Kalamazoo, MI, USA) was introduced into the common carotid artery and angiography was performed to evaluate the EICA lesion. The applied endovascular technique was left to the discretion of the physician. In general, the anterograde approach (proximal-to-distal) was applied. A microwire (Roadrunner, Cook Medical, Bloomington, IN, USA) was navigated through the EICA occlusion up to the petrosus segment. At this point the carotid artery stenting (Roadsaver, Boston Scientific, Marlborough, MA, USA; Wallstent, Boston Scientific, Marlborough, MA, USA) with balloon angioplasty (Aviator, Cordis, Santa Clara, CA, USA; Sterling, Boston Scientific, Marlborough, MA, USA) was performed under flow arrest, after this maneuver the aspiration catheter was navigated into the level of LVO and the intracranial MT was performed. MT was performed with a direct aspiration catheter (SOFIA, Microvention, Aliso Viejo, CA, USA) or in combination with a stent-retriever (SOFIA; Solitaire-FR, EV3, Irvine, CA, USA) if it was necessary.

The BAO technique was used primarily in high-risk patients with increased hemorrhagic diathesis, because of the unnecessity of periprocedural antiplatelet therapy and less traumatic effect for the vessels. In these patients a transform balloon (Aviator, Cordis, Santa Clara, CA, USA; Sterling, Boston Scientific, USA) was placed into the catheter to the level of the ICA lesion and was inflated submaximally. The catheter with the inflated balloon gently traversed through the affected segment. The atherosclerotic wall depositions of ICA were removed with manual aspiration, following which, thrombectomy was performed.

The thrombolysis in cerebral infarction (TICI) score was assessed on digital subtraction angiography at the end of the procedure. Successful recanalization was defined as TICI $2 b$ or 3 [21].

\subsection{Antiplatelet Regimen}

During the procedure, a $500 \mathrm{mg}$ bolus of aspirin IV was administered directly prior to acute stenting. No periprocedural anti-aggregation was given in the BAO group. After the procedure, every patient received a preventive dosage of low-molecular-weight heparin (LMWH) to prevent deep vein thrombosis and pulmonary embolism. After the exclusion of the hemorrhagic transformation on the 24-h control image, dual antiplatelet therapy with oral acetylsalicylic acid at $100 \mathrm{mg}$ and clopidogrel at $75 \mathrm{mg}$ daily was initiated in the stenting group and continued for 3 months. As secondary prevention, BAO patients received anti-platelet monotherapy with oral acetylsalicylic acid at $100 \mathrm{mg}$ lifelong [22].

\subsection{Follow-Up}

Early neurologic improvement was assessed based on the 24-h and 72-h NIHSS score after admission. A control CT scan was performed to evaluate the infarction volume 
and hemorrhagic status $24 \mathrm{~h}$ after the procedure. The hemorrhagic transformations were classified according to the European Cooperative Acute Stroke Study (ECASS II) classification [23]. Symptomatic intracranial hemorrhage (sICH) was defined as parenchymal hematoma (PH1 and PH2) with increase of 4 points on the NIHSS. The carotid stent patency was examined with duplex ultrasound by the departments' stroke neurologists $24 \mathrm{~h}$ after the procedure.

The primary outcome was the modified Rankin scale (mRS) score at 90 days with scores ranging from 0 (no symptoms) to 6 (death), mRS 0-2 being considered a good functional outcome. Safety endpoints were sICH and 90-day all cause-mortality.

\subsection{Statistical Analysis}

Data analysis was performed using SPSS (version 26.0, IBM, New York). The Kolmogorov-Smirnov test was used to test normality. Data is presented as mean \pm SD or median and interquartile range, where appropriate. Categorical data were compared using the $\mathrm{X}^{2}$ or the Fisher exact test. Student $\mathrm{t}$ test or Mann-Whitney U test were used for the comparison of continuous variables. Binary logistic regression analysis was used to assess the association between baseline data and outcomes. Adjustment was made for potential confounders, variables with $p<0.1$ in the univariate analysis were entered into the multivariable logistic regression model. A $p$ value of $<0.05$ was considered statistically significant.

\section{Results}

Altogether we enrolled 101 patients with acute stroke due to tandem occlusion that was treated by endovascular approach between November 2017 and December 2020 in the three participating institutions. EICA was treated with ACS in 72 (71.3\%) and BAO in 29 $(28.7 \%)$ patients. The characteristics of the overall population is summarized in Table 1 and subgroups based on EICA treating method in Table 2.

The mean age $( \pm S D)$ was $67 \pm 10$ years and patients were predominantly male $(61.4 \%)$. Forty-nine patients $(48.5 \%)$ arrived by secondary transport to the neurovascular centers. Patients with BAO were slightly older (66 \pm 10 vs. $70 \pm 9, p=0.054)$, and had higher prevalence of comorbidities such as hypertension (100.0\% vs. 59.4\%, $p<0.001)$. Intracranial occlusion sites were tICA in 30 patients (29.7\%), MCA M1 in 55 patients $(54.5 \%)$ and MCA M2 in 16 patients (15.8\%). The median baseline NIHSS was 12 (IQR 9-16) with median ASPECTS 9 (IQR 8-9) and median mCTA 4 (IQR 3-4) without significant differences. Prior IVT before thrombectomy was administered in 27 patients $(26.7 \%)$.

Regarding the details of intervention, the median symptom onset to arterial puncture time was 347 (IQR 230-655) minutes. The procedure time was slightly shorter in the BAO group (43, IQR 30-60 vs. 49, IQR 33-65, $p=0.450)$, however the difference was not significant.

Successful recanalization was achieved in $83.2 \%$ of the patients and was more frequent in the ACS group (86.1\% vs. $75.9 \%, p=0.213)$, furthermore the number of complications during the procedure $(9.7 \%$ vs. $3.4 \%, p=0.291)$ and incidence of distal embolization $(39.1 \%$ vs. $17.9 \%, p=0.043)$ showed an upward trend towards for acute stent treatment. Symptomatic intracranial hemorrhage $(\mathrm{sICH})$ was detected in 7 patients $(6.9 \%)$, however, there was a slightly higher occurrence of bleeding events, $\mathrm{aICH}(20.0 \%$ vs. $10.7 \%, p=0.273)$ and $\mathrm{sICH}(8.3 \%$ vs. $3.4 \%, p=0.382)$ in the ACS group. 
Table 1. Demographic variables and clinical parameters of overall patient population.

\begin{tabular}{|c|c|}
\hline & $\begin{array}{l}\text { TO Patients } \\
(\mathrm{N}=101)\end{array}$ \\
\hline Age, years, mean $( \pm S D)$ & $67( \pm 10)$ \\
\hline Gender, female, \% (n) & $38.6(39)$ \\
\hline Smoking, \% $(n)$ & $66.2(43)$ \\
\hline Alcohol, \% (n) & $38.5(25)$ \\
\hline Hypertension, \% (n) & $71.4(70)$ \\
\hline Diabetes mellitus, \% (n) & $20.6(20)$ \\
\hline Dyslipidemia, \% (n) & $45.4(44)$ \\
\hline Atrial fibrillation, \% $(n)$ & $19.8(20)$ \\
\hline Previous stroke \% $(n)$ & $18.1(17)$ \\
\hline Antiplatelet inhibitor therapy at admission, \% $(n)$ & $22.8(21)$ \\
\hline Aspirin, $\%(n)$ & $47.6(10)$ \\
\hline Clopidogrel, $\%(n)$ & $33.3(7)$ \\
\hline Dual antiplatelet (Aspirin + Clopidogrel), \% (n) & $19.0(4)$ \\
\hline Oral anticoagulant therapy at admission, $\%(n)$ & $8.7(8)$ \\
\hline NIHSS baseline, median (IQR) & $12(9-16)$ \\
\hline NIHSS 24h, median (IQR) & $8(4-13)$ \\
\hline NIHSS 72h, median (IQR) & $7(4-11)$ \\
\hline Early ischemic sign on admission CT, \% (n) & $70.7(70)$ \\
\hline ASPECTS, median (IQR) & $9(8-9)$ \\
\hline mCTA score, median (IQR) & $4(3-4)$ \\
\hline LVO site & \\
\hline $\mathrm{tICA}, \%(n)$ & $29.7(30)$ \\
\hline MCA M1, \% $(n)$ & $54.5(55)$ \\
\hline MCA M2, \% $(n)$ & $15.8(16)$ \\
\hline Contralateral EICA stenosis, \% (n) & $22.7(22)$ \\
\hline Primary transport, $\%(n)$ & $51.5(52)$ \\
\hline Symptom to arterial puncture time median (IQR) & $347(230-655)$ \\
\hline Puncture to revascularization time, median (IQR) & $47(33-64)$ \\
\hline Symptom onset to revascularization, median (IQR) & $400(275-725)$ \\
\hline IVT prior MT, \% (n) & $26.7(27)$ \\
\hline First pass effect, $\%(n)$ & $53.6(52)$ \\
\hline $\mathrm{TICI} \geq 2 \mathrm{~b}, \%(n)$ & $83.2(84)$ \\
\hline Aspiration catheter, \% $(n)$ & $79.2(80)$ \\
\hline Combined MT, \% (n) & $20.8(21)$ \\
\hline Complications, \% (n) & $7.9(8)$ \\
\hline None, \% $(n)$ & $92.1(93)$ \\
\hline Dissection, \% $(n)$ & $3.0(3)$ \\
\hline Perforation, $\%(n)$ & $1.0(1)$ \\
\hline $\mathrm{SAH}, \%(n)$ & $3.0(3)$ \\
\hline Other, $\%(n)$ & $1.0(1)$ \\
\hline Distal embolization, \% (n) & $33.0(32)$ \\
\hline $\mathrm{aICH}, \%(n)$ & $17.3(17)$ \\
\hline $\mathrm{sICH}, \%(n)$ & $6.9(7)$ \\
\hline 90 -day $m R S \leq 2, \%(n)$ & $53.6(52)$ \\
\hline 90-day mortality, \% (n) & $20.6(20)$ \\
\hline \multicolumn{2}{|c|}{$\begin{array}{l}\text { Abbreviations: TO, tandem occlusion; SD, standard deviation; IQR, interquartile range; NIHSS, National Institutes } \\
\text { of Health Stroke Scale; ASPECTS, Alberta Stroke Program Early CT Score; mCTA, multiphase CT-angiography; } \\
\text { LVO, large vessel occlusion; EICA, extracranial internal carotid artery; IVT, intravenous thrombolysis; TICI, } \\
\text { thrombolysis in cerebral infarction; MT, mechanical thrombectomy; SAH, subarachnoidal hemorrhage; sICH, } \\
\text { symptomatic intracranial hemorrhage; aICH asymptomatic intracranial hemorrhage; mRS, modified Rankin scale. }\end{array}$} \\
\hline
\end{tabular}


Table 2. Evaluated parameters in acute carotid stenting (ACS) and balloon angioplasty only (BAO) patient groups.

\begin{tabular}{|c|c|c|c|}
\hline & $\begin{array}{c}\text { ACS } \\
(N=72)\end{array}$ & $\begin{array}{c}\text { BAO } \\
(N=29)\end{array}$ & $p$ \\
\hline Age, years, mean $( \pm S D)$ & $66 \pm 10$ & $70 \pm 9$ & 0.054 \\
\hline Gender, female, \% $(n)$ & $34.7(25)$ & $48.3(14)$ & 0.206 \\
\hline Smoking, \% $(n)$ & $66.0(31)$ & $66.7(12)$ & 0.957 \\
\hline Alcohol, \% (n) & $38.3(18)$ & $38.9(7)$ & 0.965 \\
\hline Hypertension, \% (n) & $59.4(41)$ & $100.0(29)$ & $<0.001$ \\
\hline Diabetes mellitus, \% ( $n)$ & $20.3(14)$ & $21.4(6)$ & 0.900 \\
\hline Atrial fibrillation, \% $(n)$ & $16.7(12)$ & $27.6(8)$ & 0.213 \\
\hline Dyslipidemia, \% $(n)$ & $42.6(29)$ & $51.7(15)$ & 0.411 \\
\hline Previous stroke $\%(n)$ & $19.4(13)$ & $14.8(4)$ & 0.601 \\
\hline API therapy at admission, $\%(n)$ & $18.2(12)$ & $34.6(9)$ & 0.091 \\
\hline OAC therapy at admission, $\%(n)$ & $6.1(4)$ & $15.4(4)$ & 0.153 \\
\hline NIHSS baseline, median (IQR) & $12(9-16)$ & $13(9-16)$ & 0.450 \\
\hline NIHSS 24h, median (IQR) & $8(4-13)$ & $8(6-11)$ & 0.591 \\
\hline NIHSS 72h, median (IQR) & $7(4-10)$ & $8(6-11)$ & 0.432 \\
\hline ASPECTS, median (IQR) & $8(8-9)$ & $9(8-9)$ & 0.213 \\
\hline mCTA score, median (IQR) & $4(3-4)$ & $4(3-4)$ & 0.938 \\
\hline First pass effect, $\%(n)$ & $55.1(38)$ & $50.0(14)$ & 0.650 \\
\hline TICI $\geq 2 b, \%(n)$ & $86.1(62)$ & $75.9(22)$ & 0.213 \\
\hline $\begin{array}{c}\text { Symptom onset to arterial puncture time } \\
\text { median (IQR) }\end{array}$ & $360(235-655)$ & $310(215-665)$ & 0.838 \\
\hline Puncture to revascularization time, median (IQR) & $49(33-65)$ & $43(30-60)$ & 0.450 \\
\hline Symptom onset to revascularization, median (IQR) & $400(275-725)$ & $385(270-680)$ & 0.832 \\
\hline Complications, $\%(n)$ & $9.7(7)$ & $3.4(1)$ & 0.291 \\
\hline Distal embolization, \% $(n)$ & $39.1(27)$ & $17.9(5)$ & 0.043 \\
\hline $\mathrm{aICH}, \%(n)$ & $20.0(14)$ & $10.7(3)$ & 0.273 \\
\hline $\mathrm{sICH}, \%(n)$ & $8.3(6)$ & $3.4(1)$ & 0.382 \\
\hline Early stent thrombosis, $\%(n)$ & $8.8(5)$ & - & \\
\hline 90-day $\mathrm{mRS} \leq 2, \%(n)$ & $54.4(37)$ & $51.7(15)$ & 0.808 \\
\hline 90-day mortality, \% (n) & $23.5(16)$ & $13.8(4)$ & 0.278 \\
\hline
\end{tabular}

Abbreviations: ACS, acute carotid stenting; BAO, balloon angioplasty only; SD, standard deviation; IQR, interquartile range; API, antiplatelet inhibitor; OAC, oral anticoagulant; NIHSS, National Institutes of Health Stroke Scale; ASPECTS, Alberta Stroke Program Early CT Score; mCTA, multiphase CT-angiography; IVT, intravenous thrombolysis; TICI, thrombolysis in cerebral infarction; sICH, symptomatic intracranial hemorrhage; aICH asymptomatic intracranial hemorrhage; $\mathrm{mRS}$, modified Rankin scale.

In the 90-day follow-up 52 patients (53.6\%) showed favorable outcome and 20 patients (20.6\%) died. Four patients (4.0\%) were lost to follow-up. In the ACS group, 37 (54.4\%) patients achieved good functional outcome and $15(51.7 \%)$ in the BAO group. Mortality rate at 90 days was slightly lower in patients with $\mathrm{BAO}(13.8 \%$ vs. $23.5 \%, p=0.278)$. There were no significant differences in the outcomes.

Regression analysis showed that younger age $(p=0.013)$, lack of atrial fibrillation (AF) $(p=0.008)$, low baseline NIHSS score $(p=0.029)$, and successful recanalization $(p=0.023)$ were associated with favorable outcome, while older age $(p=0.046)$, alcohol consumption $(p=0.033)$, high NIHSS score at $72 \mathrm{~h}(p=0.009)$, low mCTA score $(p=0.039)$, and presence of sICH $(p=0.034)$ were associated with 90-day mortality. Distal embolization did not prove to be an independent predictor of the outcomes. Independent predictors of outcomes are summarized in Table 3.

Furthermore, we performed a subgroup analysis to compare the sICH and non-sICH patient groups, results are summarized in Table S1 in the Supplementary Material. Besides the 90-day mortality, the rate of intraprocedural complications and primary transports were higher in the sICH patient group. Although these results should be interpreted cautiously due to the low number of sICH cases. 
Table 3. Independent predictors of outcomes.

\begin{tabular}{ccc}
\hline & OR (95\% CI) & $p$ \\
\hline 90-day mRS 0-2 & & \\
Age & $0.932(0.882-0.985)$ & 0.013 \\
Atrial fibrillation & $0.142(0.034-0.600)$ & 0.008 \\
NIHSS baseline & $0.901(0.821-0.989)$ & 0.029 \\
Successful recanalization (TICI $\geq 2 b)$ & $5.653(1.271-25.145)$ & 0.023 \\
\hline 90-day mortality & & 0.046 \\
Age & $1.132(1.002-1.279)$ & 0.033 \\
Alcohol consumption & $13.356(1.239-143.935)$ & 0.009 \\
NIHSS 72h & $1.248(1.056-1.476)$ & 0.039 \\
mCTA score & $0.521(0.281-0.966)$ & 0.034 \\
sICH & $15.264(1.228-189.710)$ &
\end{tabular}

Abbreviations: OR, odds ratio; CI, confidence interval; mRS, modified Rankin scale; NIHSS, National Institutes of Health Stroke Scale; TICI, thrombolysis in cerebral infarction; mCTA, multiphase CT-angiography; sICH, symptomatic intracranial hemorrhage.

\section{Discussion}

In this multicenter analysis, patients treated with the angioplasty only technique achieved comparable favorable outcome rates to the acute stent group. However, we observed a trend towards higher rates of hemorrhages and 90-day mortality, with significantly higher frequency of distal embolization in patients with acute stenting.

Recent randomized-controlled trials have shown the superiority of EVT in LVOs over IVT alone [5-7]. However, approximately $15-20 \%$ of patients with AIS have high grade stenosis or occlusion of EICA in addition to intracranial LVO [3]. This type of acute stroke has been poorly represented in RCTs, therefore data from RCTs are limited. Consequently, there is no consensus on the optimal EVT technique of tandem lesions. Currently, singlecenter studies have presented that acute stenting of EICA is technically feasible with high success rate. However, the rate of hemorrhage events ranged from 18 to $43 \%$ and stent thrombosis in up to $17 \%$ of cases have been described [24]. Because of the aforementioned details, multiple EVT approaches have been reported, although the majority of studies deal primarily in more depth with the approach of vascular openings (proximal-to-distal or distal-to-proximal) and there are few studies and lack of guidance about the EICA opening management.

In our present study $52(53.6 \%)$ patients achieved favorable outcome at 90 days, 20 patients died $(20.6 \%)$, and sICH occurred $7(6.9 \%)$ times. Our results are consistent with the findings of previous studies and confirm the efficacy and necessity of EVT in tandem lesions [19]. However, these studies were mainly single-center studies with small numbers of BAO patients and heterogeneous periprocedural methods, furthermore, all of these studies primarily applied stent-retriever technique for MT during the procedure, whereas we used the direct aspiration technique predominantly [19]. In 2020, Xing et al. directly investigated the two MT techniques efficacy in IICA occlusions. Patients treated with the direct aspiration technique achieved significantly higher successful recanalization rates which may explain the slightly better successful recanalization rate in our study compared to previous studies (83.6\% vs. $78 \%$ ) $[19,25]$.

Furthermore, the rate of favorable outcome was slightly higher in the ACS patients' group ( $54.4 \%$ vs. $51.7 \%$ ), however, at the same time, a moderately higher proportion of hemorrhagic events (aICH, $20.0 \%$ vs. $10.7 \%$; sICH, $8.3 \%$ vs. $3.4 \%$ ) and 90 -day mortality ( $23.5 \%$ vs. $13.8 \%$ ) were observed. The intravenous antiplatelet therapy directly prior to carotid stenting may be the explanation of the relatively higher hemorrhage events, however, it is necessary to prevent acute stent thrombosis. Currently only few data are available for periprocedural antiplatelet management of acute carotid stenting during EVT [22]. Based on the latest antiplatelet Delphi consensus, aspirin IV (500 mg bolus) should be used as the first-line agent prior to carotid stenting [22]. Although Da Ros et al. identified potential predictors for sICH as the higher intraprocedural heparin dosage, the initial ASPECTS 
$\leq 7$ and the MT needs more than one attempt for complete recanalization [26]. However, differences were not observed in our study, probably due to the significantly lower number of sICH cases, the different periprocedural heparin management, and the lack of detailed MT attempts data (only the presence of first pass effect was documented).

In our study, $20 \%$ of patients had AF and 29 patients received antithrombotic medication at admission. Therefore, our study's population had an increased hemorrhagic diathesis, which was further increased by the prior IVT (26.7\%). Besides the neurointerventionalist's individual discretion, every patient's individual bleeding risk was also assessed and considered before choosing the EVT strategy.

ACS patients with AF are recommended postprocedural triple inhibition based on expert opinion, however, it has been proven to raise the bleeding rates $[27,28]$. Our results suggest that these bleeding events could probably be avoided by treating EICA with BAO.

Data are also limited in terms of stent patency at the subacute phase of patients with TO. The mechanism of thrombus formation related to mutual interaction between the coagulation system and platelet activator system is due to vascular endothelial damage and individual patient-, lesion-, and stent-related factors (poor stent expansion, delayed endothelization, inflammation reactions) $[27,29]$. Five $(8.8 \%)$ subacute stent thrombosis were detected by $24-\mathrm{h}$ carotid ultrasound in our study. This stent thrombosis rate is similar that reported by Wallocha et al. (5.6\%) [30].

Only few previous studies investigated the rate of distal embolization according to the interventional technique. Li et al. reported that they found higher distal embolic rate in the angioplasty only group [31]. However, occurrence of distal embolization in our study was significantly higher in patients with ACS $(39.1 \%$ vs. $17.9 \%, p=0.043)$. The difference can be explained with our PTA technique in the BAO group, which was very similar to the balloon assisted technique (BAT) in cardiology, therefore, after the submaximally inflated balloon was gently traversed to the entire affected segment, then manual aspiration of atherosclerotic deposits was performed $[32,33]$.

The main strength of our study is the thorough investigation of EVT strategies in TO including the treatment technique with direct aspiration catheter and with the unique balloon angioplasty technique. The evaluation of the rate of distal embolization according to the EVT technique should also be highlighted as it had not been observed in previous larger studies. However, our study has several limitations. Firstly, this is a nonrandomized retrospective analysis with a relatively small number of patients. Secondly, the heterogeneity of treating methods due to different endovascular approaches between centers may have affected the outcomes. Finally, due to retrospective registry design we cannot rule out the existence of potentially important variables that were not included in our analysis.

\section{Conclusions}

In conclusion, an endovascular approach of EICA in addition to MT was safe and effective in tandem occlusion of anterior circulation, regardless of the opening technique. However, our results suggest that the balloon angioplasty technique without acute stenting showed a comparably favorable outcome rate as a contrast to ACS with moderately less hemorrhagic events and mortality rates, therefore, BAO may be a suitable alternative treatment for patients with high bleeding risk. A prospective randomized study would be warranted to specifically clarify the best treatment strategies for patient groups.

Supplementary Materials: The following are available online at https:/ /www.mdpi.com/article/10 $.3390 /$ life11050458/s1, Table S1: Evaluated parameters in patients with and without sICH.

Author Contributions: P.J.K. designed the study, performed literature search, data acquisition and analysis, statistical analysis, and wrote the manuscript; G.T. performed data acquisition, data analysis and reviewed the manuscript; C.B.N., P.C., G.L., A.A. and I.S. performed data acquisition and reviewed the manuscript; Z.N.K. and E.B. performed the literature search, data acquisition, and reviewed the manuscript; A.B. and L.S. designed the concepts of the study, interpreted the data, reviewed, and approved the manuscript; L.S. is the guarantor. All authors have read and agreed to the published version of the manuscript. 
Funding: In this study we used data from the STAY ALIVE Acute Stroke Registry, the operation of which was funded by the Economic Development and Innovation Operative Programme Grant (GINOP 2.3.2-15-2016-00048). None of the authors received personalized funding for this work.

Institutional Review Board Statement: The study protocol was approved by the Hungarian Medical Research Council (35403-2/2017/EKU).

Informed Consent Statement: Written informed consent was obtained from each patient according to the Good Clinical Practice (GCP) guidelines.

Data Availability Statement: The data presented in this study are available on request from the corresponding author. The data are not publicly available due to patient privacy considerations (HIPPA).

Conflicts of Interest: The authors declare no conflict of interest.

\section{References}

1. Politi, M.; Kastrup, A.; Marmagkiolis, K.; Grunwald, I.Q.; Papanagiotou, P. Endovascular therapy for acute stroke. Prog. Cardiovasc. Dis. 2017, 59, 534-541. [CrossRef] [PubMed]

2. White, C.J.; Abou-Chebl, A.; Cates, C.U.; Levy, E.I.; McMullan, P.W.; Rocha-Singh, K.; Weinberger, J.M.; Wholey, M.H. Stroke intervention: Catheter-based therapy for acute ischemic stroke. J. Am. Coll. Cardiol. 2011, 58, 101-116. [CrossRef] [PubMed]

3. Grau, A.J.; Weimar, C.; Buggle, F.; Heinrich, A.; Goertler, M.; Neumaier, S.; Glahn, J.; Brandt, T.; Hacke, W.; Diener, H.C. Risk factors, outcome, and treatment in subtypes of ischemic stroke: The German stroke data bank. Stroke 2001, 32, 2559-2566. [CrossRef] [PubMed]

4. Seet, R.C.; Wijdicks, E.F.; Rabinstein, A.A. Stroke from acute cervical internal carotid artery occlusion: Treatment results and predictors of outcome. Arch. Neurol. 2012, 69, 1615-1620. [CrossRef]

5. Berkhemer, O.A.; Fransen, P.S.; Beumer, D.; van den Berg, L.A.; Lingsma, H.F.; Yoo, A.J.; Schonewille, W.J.; Vos, J.A.; Nederkoorn, P.J.; Wermer, M.J.; et al. A randomized trial of intraarterial treatment for acute ischemic stroke. N. Engl. J. Med. 2015, 372, 11-20. [CrossRef] [PubMed]

6. Goyal, M.; Demchuk, A.M.; Menon, B.K.; Eesa, M.; Rempel, J.L.; Thornton, J.; Roy, D.; Jovin, T.G.; Willinsky, R.A.; Sapkota, B.L.; et al. Randomized assessment of rapid endovascular treatment of ischemic stroke. N. Engl. J. Med. 2015, 372, 1019-1030. [CrossRef] [PubMed]

7. Saver, J.L.; Goyal, M.; Bonafe, A.; Diener, H.C.; Levy, E.I.; Pereira, V.M.; Albers, G.W.; Cognard, C.; Cohen, D.J.; Hacke, W.; et al. Stent-retriever thrombectomy after intravenous t-PA vs. t-PA alone in stroke. N. Engl. J. Med. 2015, 372, 2285-2295. [CrossRef] [PubMed]

8. Campbell, B.C.; Mitchell, P.J.; Kleinig, T.J.; Dewey, H.M.; Churilov, L.; Yassi, N.; Yan, B.; Dowling, R.J.; Parsons, M.W.; Oxley, T.J.; et al. Endovascular therapy for ischemic stroke with perfusion-imaging selection. N. Engl. J. Med. 2015, 372, 1009-1018. [CrossRef]

9. Goyal, M.; Wilson, A.T.; Kamal, N.; McTaggart, R.A.; Jayaraman, M.V.; Fisher, M.; Hill, M.D. Amartya Sen and the organization of endovascular stroke treatment. Stroke 2017, 48, 2310-2312. [CrossRef]

10. Jovin, T.G.; Chamorro, A.; Cobo, E.; de Miquel, M.A.; Molina, C.A.; Rovira, A.; San Román, L.; Serena, J.; Abilleira, S.; Ribó, M.; et al. Revascat Trial Investigators. Thrombectomy within 8 hours after symptom onset in ischemic stroke. N. Engl. J. Med. 2015, 372, 2296-2306. [CrossRef]

11. Powers, W.J.; Rabinstein, A.A.; Ackerson, T.; Adeoye, O.M.; Bambakidis, N.C.; Becker, K.; Biller, J.; Brown, M.; Demaerschalk, B.M.; Hoh, B.; et al. Guidelines for the Early Management of Patients With Acute Ischemic Stroke: 2019 Update to the 2018 Guidelines for the Early Management of Acute Ischemic Stroke: A Guideline for Healthcare Professionals From the American Heart Association/American Stroke Association. Stroke 2019, 50, 344-418.

12. Saqqur, M.; Uchino, K.; Demchuk, A.M.; Molina, C.A.; Garami, Z.; Calleja, S.; Akhtar, N.; Orouk, F.O.; Salam, A.; Shuaib, A.; et al. Site of arterial occlusion identified by transcranial Doppler predicts the response to intravenous thrombolysis for stroke. Stroke 2007, 3, 948-954. [CrossRef] [PubMed]

13. Rubiera, M.; Ribo, M.; Delgado-Mederos, R.; Santamarina, E.; Delgado, P.; Montaner, J.; Alvarez-Sabín, J.; Molina, C.A. Tandem internal carotid artery/middle cerebral artery occlusion: An independent predictor of poor outcome after systemic thrombolysis. Stroke 2006, 37, 2301-2305. [CrossRef] [PubMed]

14. Kim, Y.S.; Garami, Z.; Mikulik, R.; Molina, C.A.; Alexandrov, A.V.; Collaborators, C. Early recanalization rates and clinical outcomes in patients with tandem internal carotid artery/middle cerebral artery occlusion and isolated middle cerebral artery occlusion. Stroke 2005, 36, 869-871. [CrossRef] [PubMed]

15. Bücke, P.; Aguilar Pérez, M.; AlMatter, M.; Hellstern, V.; Bäzner, H.; Henkes, H. Functional Outcome and Safety of Intracranial Thrombectomy After Emergent Extracranial Stenting in Acute Ischemic Stroke Due to Tandem Occlusions. Front. Neurol. 2018, 9 , 940. [CrossRef] [PubMed] 
16. Assis, Z.; Menon, B.K.; Goyal, M.; Demchuk, A.M.; Shankar, J.; Rempel, J.L.; Roy, D.; Poppe, A.Y.; Yang, V.; Lum, C.; et al. Acute ischemic stroke with tandem lesions: Technical endovascular management and clinical outcomes from the escape trial. $J$. Neurointerv. Surg. 2018, 10, 429-433. [CrossRef]

17. Sivan-Hoffmann, R.; Gory, B.; Armoiry, X.; Goyal, M.; Riva, R.; Labeyrie, P.E.; Lukaszewicz, A.C.; Lehot, J.J.; Derex, L.; Turjman, F. Stent-retriever thrombectomy for acute anterior ischemic stroke with tandem occlusion: A systematic review and metaanalysis. Eur. Radiol. 2017, 27, 247-254. [CrossRef]

18. Rangel-Castilla, L.; Rajah, G.B.; Shakir, H.J.; Shallwani, H.; Gandhi, S.; Davies, J.M.; Snyder, K.V.; Levy, E.I.; Siddiqui, A.H. Management of acute ischemic stroke due to tandem occlusion: Should endovascular recanalization of the extracranial or intracranial occlusive lesion be done first? Neurosurg. Focus 2017, 42, E16. [CrossRef]

19. Wilson, M.P.; Murad, M.H.; Krings, T.; Pereira, V.M.; O’Kelly, C.; Rempel, J.; Hilditch, C.A.; Brinjikji, W. Management of tandem occlusions in acute ischemic stroke-intracranial versus extracranial first and extracranial stenting versus angioplasty alone: A systematic review and meta-analysis. J. Neurointerv. Surg. 2018, 10, 721-728. [CrossRef]

20. Ferguson, G.G.; Eliasziw, M.; Barr, H.W.; Clagett, G.P.; Barnes, R.W.; Wallace, M.C.; Taylor, D.W.; Haynes, R.B.; Finan, J.W.; Hachinski, V.C.; et al. The North American Symptomatic Carotid Endarterectomy Trial: Surgical results in 1415 patients. Stroke 1999, 9, 1751-1758. [CrossRef]

21. Zaidat, O.O.; Yoo, A.J.; Khatri, P.; Tomsick, T.A.; von Kummer, R.; Saver, J.L.; Marks, M.P.; Prabhakaran, S.; Kallmes, D.F.; Fitzsimmons, B.F.; et al. Recommendations on Angiographic Revascularization Grading Standards for Acute Ischemic Stroke: A Consensus Statement. Stroke 2013, 44, 2650-2663. [CrossRef] [PubMed]

22. Goyal, M.; Yoshimura, S.; Milot, G.; Fiehler, J.; Jayaraman, M.; Dorn, F.; Taylor, A.; Liu, J.; Albuquerque, F.; Jensen, M.E.; et al. Considerations for Antiplatelet Management of Carotid Stenting in the Setting of Mechanical Thrombectomy: A Delphi Consensus Statement. Am. J. Neuroradiol. 2020, 41, 2274-2279. [CrossRef]

23. Hacke, W.; Kaste, M.; Fieschi, C.; von Kummer, R.; Davalos, A.; Meier, D.; Larrue, V.; Bluhmki, E.; Davis, S.; Donnan, G.; et al. Randomised double-blind placebo-controlled trial of thrombolytic therapy with intravenous alteplase in acute ischaemic stroke (ECASS II). Second European-Australasian Acute Stroke Study Investigators. Lancet 1998, 17, 1245-1251. [CrossRef]

24. Jadhav, A.P.; Zaidat, O.O.; Liebeskind, D.S.; Yavagal, D.R.; Haussen, D.C.; Hellinger, F.R., Jr.; Jahan, R.; Jumaa, M.A.; Szeder, V.; Nogueira, R.G.; et al. Emergent management of tandem lesions in acute ischemic stroke. Stroke 2019, 50, 428-433. [CrossRef] [PubMed]

25. Xing, P.F.; Yang, P.F.; Li, Z.F.; Zhang, L.; Shen, H.J.; Zhang, Y.X.; Zhang, Y.W.; Liu, J.M. Comparison of Aspiration versus Stent Retriever Thrombectomy as the Preferred Strategy for Patients with Acute Terminal Internal Carotid Artery Occlusion: A Propensity Score Matching Analysis. Am. J. Neuroradiol. 2020, 41, 469-476. [CrossRef] [PubMed]

26. Da Ros, V.; Scaggiante, J.; Sallustio, F.; Lattanzi, S.; Bandettini, M.; Sgreccia, A.; Rolla-Bigliani, C.; Lafe, E.; Sanfilippo, G.; Diomedi, M.; et al. Carotid Stenting and Mechanical Thrombectomy in Patients with Acute Ischemic Stroke and Tandem Occlusions: Antithrombotic Treatment and Functional Outcome. Am. J. Neuroradiol. 2020, 41, 2088-2093. [CrossRef] [PubMed]

27. Enomoto, Y.; Yoshimura, S. Antiplatelet therapy for carotid artery stenting. Interv. Neurol. 2013, 1, 151-163. [CrossRef] [PubMed]

28. Dewilde, W.J.; Oirbans, T.; Verheugt, F.W.; Kelder, J.C.; De Smet, B.J.; Herrman, J.P.; Adriaenssens, T.; Vrolix, M.; Heestermans, A.A.; Vis, M.M.; et al. Woest study investigators. Use of clopidogrel with or without aspirin in patients taking oral anticoagulant therapy and undergoing percutaneous coronary intervention: An open-label, randomised, controlled trial. Lancet 2013, 381, 1107-1115. [CrossRef]

29. Kirtane, A.J.; Stone, G.W. How to minimize stent thrombosis. Circulation 2011, 124, 1283-1287. [CrossRef]

30. Wallocha, M.; Chapot, R.; Nordmeyer, H.; Fiehler, J.; Weber, R.; Stracke, C.P. Treatment Methods and Early Neurologic Improvement After Endovascular Treatment of Tandem Occlusions in Acute Ischemic Stroke. Front. Neurol. 2019, 10, 127. [CrossRef]

31. Li, W.; Chen, Z.; Dai, Z.; Liu, R.; Yin, Q.; Wang, H.; Hao, Y.; Han, Y.; Qiu, Z.; Xiong, Y.; et al. Management of acute tandem occlusions: Stent-retriever thrombectomy with emergency stenting or angioplasty. J. Int. Med. Res. 2018, 46, 2578-2586. [CrossRef] [PubMed]

32. Wojciuk, J.; Beijk, M.A.; Goode, G.; Brack, M.; Galasko, G.; More, R.; Roberts, D.; Eichhöfer, J.; Patel, B.; Chauhan, A.; et al Balloon-assisted tracking technique as 'a way forward' for transradial intervention. Coron. Artery. Dis. 2019, 6, 440-447. [CrossRef] [PubMed]

33. Burkhardt, J.K.; Shapiro, M.; Tanweer, O.; Litao, M.; Chancellor, B.; Raz, E.; Riina, H.A.; Nelson, P.K. Balloon-assisted tracking technique to overcome intracranial stenosis during thrombectomy for stroke. BMJ Case Rep. 2018, 1, e014275. [CrossRef] [PubMed] 